\title{
The Effect of Power Imbalances on Incentives to Make Non-Contractible Investments
}

\author{
Marco Faravelli*
}

\author{
Oliver Kirchkamp ${ }^{\dagger}$
}

Helmut Rainer $\ddagger$

September 21, 2012

\begin{abstract}
We use an experiment to study the effect of ex-post sharing rules on relationshipspecific investments in an incomplete contracting context. We find that no power structure can induce first-best investments and that equally productive partners reach more efficient outcomes with a balanced power structure (i.e., equal sharing of returns) than with an asymmetric one. In addition, we find evidence for behavioural effects: partners make higher investments and reach higher efficiency levels than own-payoff maximisation would suggest. This behaviour is in line with a model where decisionmakers care about social efficiency. It is not consistent with inequality-averse preferences.

Keywords: Incomplete Contracts, Relationship-Specific Investments, Allocation of Power, Social Preferences, Experiments. JEL: C91, D23, D86.
\end{abstract}

\section{Introduction}

An essential characteristic of a successful partnership is that all parties involved have an incentive to make significant relationship-specific investments. However, it is not uncommon that one partner has more power than another and is therefore able to appropriate a large share of the overall benefits from the partnership. In a world with costly contracting, such power imbalances may affect resource allocations by shaping the incentives of individuals to undertake productive activities that enhance the value of partnership projects.

Power imbalances abound in many real world partnerships. The distinctive feature of sharecropping contracts in the agricultural sector is the division of product between tenants and landlords according to some predetermined share-out. The tenant's share of output has been observed to be as low as 20 percent in Southern India (Tomlinson, 1996, p. 81) or as high as 80 percent in Argentina in the 1890s (Adelman, 1994, p. 137). In a supplier-manufacturer relationship in the automotive industry, the supplier may have no other customer than the manufacturer. Consequently, the incentive for the manufacturer to appropriate quasi rents by negotiating a revised lower price at which it will accept parts from the supplier may be large (Klein et al. 1978). Power imbalances also exist in company-community partnerships in the developing world, particularly in the 'fair trade'

*School of Economics, University of Queensland, Colin Clark Building, St Lucia, Brisbane, QLD 4072, Australia, m.faravelli@uq.edu.au.

$\left.{ }^{\dagger} \otimes\right)$ School of Economics, University of Jena, Carl-Zeiss-Str. 3, 07743 Jena, Germany, oliver@kirchkamp.de, ๘ +493641943240 , Fix +493641943242 .

‡Ifo Institute for Economic Research at the University of Munich, Poschingerstr. 5, 81679 Munich, Germany, rainer@ifo.de. 
commercialization of non-timber forest products in Brazilian Amazonia (Morsello, 2006). Aspects of trade deals between large corporations and communities which have led to power asymmetries are premium prices and single buyers (Corry, 1993; Turner. 1995), which drastically undermine communities' negotiating power (Mayers and Vermeulen, 2002). In consequence, corporations typically appropriate larger portions of the overall benefits accruing from company-community partnerships.

The seminal work of Grossman and Hart (1986) and Hart and Moore (1990) shows the close connection between the allocation of power-as determined by the allocation of private control and property rights - and the incentives of partners to undertake relationship-specific investments. In this paper, we experimentally examine relationship-specific investments in an environment in which two partners may have different amounts of power, so that the stronger partner can appropriate a greater share of the benefits from the relationship. Since power imbalances are more the norm than the exception, this issue has broad implications for a variety of economic contexts. One main thrust of the paper is to examine the effect of power imbalances on relationship-specific investments when contracts are incomplete. Another is to examine how our experimental results can be explained with competing forms of social preferences. To this effect, we present a simple model of incomplete contracts based on social preferences, and use the theoretical results to guide our way of interpreting the data from our experiment.

Our experiment has the following main features. Two equally productive players simultaneously decide how much to invest into a joint production process. These investments cannot be specified in an ex-ante contract. The total monetary benefit from the production process is a CobbDouglas transformation of the players' respective investments. A sharing rule determines how the total monetary benefit from joint production is split between the two players. Under a symmetric or "balanced-power" partnership structure, players are entitled to (almost) equal shares of the total monetary benefit. Under an asymmetric or "imbalanced-power" partnership structure, the power-advantaged player receives a substantially larger share of the total monetary benefit than the weaker player. Throughout the experiment, we elicit not only players' own investment strategies, but also their beliefs about their partners' investment strategies.

In our experiment we start with a static situation where the power structure is fixed and exogenous. We then move to a situation where players can choose between two power structures. In the first situation with exogenous power structure we ask: How do power imbalances between trading partners affect incentives to make relationship-specific investments? What behavioural motives determine partners' investment behaviour under balanced and imbalanced power structures? We show that no allocation of power induces first best investments, but some allocations are more efficient than others. In particular, since the players are equally productive, theory predicts lower investments in the presence of power imbalances. This is confirmed in our experiment. However, we also observe that behavioural motives enter players' investment behaviour. Specifically, we find that players invest strictly more than what selfish players would invest in equilibrium. This "overinvestment" is found both under the balanced and under the imbalanced-power structure, although in the latter case we find more overinvestment among strong players. We show that this behaviour is consistent with preferences for social efficiency (Charness and Rabin, 2002). It cannot be explained by inequality aversion (Fehr and Schmidt. 1999).

Next, we allow players to choose between two power structures and ask: Under what conditions would a player which is advantaged by an asymmetric sharing rule agree to "tie her hands" and sign a contract that establishes symmetric sharing? For example, in a company-community deal in a developing country, a large corporation may have to decide whether to agree to contracts and mechanisms that allow fairer negotiations between the trade partners (Morsello, 2006). To address this issue, players first gain experience with exogenous symmetric and asymmetric sharing rules. In a second part of the experiment players are allowed to switch from an asymmetric rule to a symmetric one. This switch requires mutual consent. Theory predicts that the disadvantaged 
player always has an incentive to switch to a more symmetric rule $1^{1}$ For the advantaged player the situation is less clear: switching to a symmetric rule generates better incentives for total investment but also reduces this player's share of the joint profit. We analyse two situations, one in which it is individually rational for strong players to switch to a more equal structure, and one in which they should theoretically refuse to do so. Our key results are the following. Disadvantaged players almost always vote for a balanced-power partnership structure, as one would expect. What is more intriguing is the behaviour of advantaged players: a majority of strong players are willing to give up their strong position irrespective of whether it is individually rational or not. However, there are also participants who are disinclined to abandon power even when the principle of own-payoff maximisation tells them to do so.

The remainder of the paper is organised as follows. Section 2 discusses the related experimental literature. Section 3 describes the experimental features and setup. Section 4 generates behavioural predictions. Section 5 presents the results. Section 6 concludes.

\section{Related Experiments}

Despite the mounting evidence that economic agents exhibit social preferences (Fehr and Schmidt, 1999: Bolton and Ockenfels, 2000; Charness and Rabin, 2002), scholars have only recently started to study incomplete contracts in a context where decision makers have social preferences (Hart, 2008; Hart and Moore, 2008). Hold-up problems have been studied in the laboratory by Hacket (1994) and later by Oosterbeek et al. (2003), and Ellingsen and Johannesson (2004a b). Here we are not interested in the hold-up, i.e. in the possibility of bargaining after the investment stage. Instead we look at a situation where profit is observable and verifiable and contracts on profit can be written ex ante. We are still in a world where actions are not verifiable, i.e. part of the incomplete contracting problem remains.

A close antecedent to this paper is Fehr et al. (2008) who use experiments to compare different allocations of ownership rights ${ }^{2}$ The key finding of their study, which contrasts with the theoretical prediction of the property rights model developed by Hart (1995), is that joint ownership can be the most efficient ownership structure. The superiority of joint ownership in their experimental setting can be explained by the fact that it makes better use of reciprocity as an enforcement device than alternative ownership structures. Although some of the issues we are interested in are similar to those explored in Fehr et al. (2008), our setup differs markedly from theirs.

First and most importantly, in our experiment players invest simultaneously while Fehr et al. study sequential investments. Theoretical (Varian, 1994) as well es experimental (Gächter et al., 2009) evidence suggests that investments in sequential games often differ markedly from investments in simultaneous games. The partnerships that we mention in the introduction, i.e. sharecropping contracts, supplier-manufacturer relationships, company-community partnerships, etc., are typically not sequential. Participants have to make their investments rather simultaneously without fully knowing the investment of the other party. Second, we employ a non-linear payoff function instead of a linear one. Players receive payoffs based on a Cobb-Douglas transformation of their investments into a physical asset. Investments are therefore complements at the margin, and the equilibrium outcome is interior rather than on the boundary of the strategy space. Third, we not only observe players' investment strategies, but also players' beliefs about their opponents' investment strategies. This allows us to learn more about the motives of the players $\mathrm{3}^{3}$

\footnotetext{
${ }^{1}$ This is because both total investments and weak players' shares of the benefits would increase.

${ }^{2}$ Another exception is the study by Fehr et al. (2011) which provides experimental evidence in line with the idea of Hart and Moore (2008) that competitively determined contracts constitute a reference point for trading relationships. 3 Iriberri and Rey-Biel (2008) find that different social preferences of participants in their experiment with modified dictator games are clearly related to different beliefs about others' actions.
} 
Several experimental papers focus on the identification and categorisation of different types of social preferences (see, for instance Andreoni and Miller, 2002). The experimental evidence we present is consistent with preferences for social welfare. Relatedly, Charness and Grosskopf (2001) show that most people in simple experimental games are prepared to make monetary sacrifices to help other persons, but only few sacrifice money to achieve equality of payoffs. Kritikos and Bolle (2001) discriminate among different types of distributional concerns and show that participants in binary-choice dictator games care about efficiency rather than equity. Engelmann and Strobel (2004) study simple one-shot distribution experiments, showing that a combination of efficiency concerns, max-min preferences, and selfishness can rationalise most of their data while inequality aversion cannot explain some important patterns. Fisman et al. (2007) also find that subjects are more inclined to increase aggregate payoffs rather than to reduce inequality. Similar results are obtained by Cox and Sadiraj (2011) and Cox et al. (2007). While the focus of these papers is rather on social preferences per se we look here at the specific economic context of incentives to make non-contractible investment. Finally, a recent experimental study by Cabrales et al. (2010) is similar in spirit to ours, in that it explores the impact of social preferences on markets and contracts. Their results also fit the general pattern described above: subjects are less concerned with equality than with the robustness of the contract and, whenever it is selected, the egalitarian contract leads to the inefficient outcome.

Our paper also makes contact with several other strands of the experimental literature. Our investment game clearly shares some features with public good games, which have been extensively explored in the laboratory. A common finding is that in public good games people invest more than selfish players would invest in the Nash equilibrium. Our symmetric partnership structure is reminiscent of non-linear public good games with interior Nash equilibria (for a review of the relevant experimental literature see Holt and Laury, 2008). However, experiments with public good games usually study a situation where the joint product is shared equally among all players. In this paper we look at situations where players need not have the same bargaining power and, hence, shares of the joint product can be asymmetric.

\section{Implementation of the Experiment}

\subsection{Baseline Game and Experimental Design}

Consider the following model. There are two agents, $A$ and $B$. Each agent $i \in\{A, B\}$ owns $M_{i}$ units of initial endowment of a private good. Agents choose how to split $M_{i}$ between their own consumption $\left(x_{i}\right)$ and investment $\left(I_{i}\right)$ in a production process. The monetary value of the output produced by the investments of $A$ and $B$ is given by $Q\left(I_{A}, I_{B}\right)=\left(I_{A} I_{B}\right)^{\alpha} \cdot \vartheta$, where $\vartheta>0$ and $\alpha>0$ are productivity parameters. A sharing rule (or an allocation of power) determines how the monetary value of output is split between the agents. Let $\pi_{A}=\pi$ be the share that goes to $A$, and let $\pi_{B}=1-\pi$ be the share that goes to $B$. Each (selfish) agent $i$ maximises a payoff function of the form $U_{i}\left(I_{A}, I_{B}\right)=x_{i}+\pi_{i} Q\left(I_{A}, I_{B}\right)$ subject to the constraint $M_{i}=x_{i}+I_{i}$. Throughout the paper, we assume that players are equally productive, i.e. the exponent $\alpha$ in the Cobb-Douglas function is the same for both players.

Our experiment is based on the above basic model and was run at the University of Jena (Germany) in June and July 2008. It was computerised using z-Tree (Fischbacher. 2007). A total of 146 participants, recruited with Orsee (Greiner, 2004), took part in the experiment. A translation of the instructions can be found in Appendix B. Table 1 is useful in explaining the general structure of the experiment: participants were assigned to one of our two configurations: conflict and no conflict. Within each configuration, participants experience (within subject) three treatments: an asymmetric contract (ASYM), a symmetric contract (SYM) and a flexible contract (FLEX). In ASYM 


\begin{tabular}{l|c|c|c|c}
\hline \multicolumn{1}{l}{ Table 1 List of experimental treatments } \\
\hline Configuration & SYM & ASYM & FLEX & $n$ \\
\hline conflict $(-\mathrm{C})$ & SYM-C & ASYM-C & FLEX-C, choice between & 8 sessions \\
$\vartheta=24.83, \alpha=0.359$ & $\pi=0.491$ & $\pi=0.708$ & $\pi=0.491$ and $\pi=0.708$ & 70 participants \\
\hline no conflict (-NC) & SYM-NC & ASYM-NC & FLEX-NC, choice between & 8 sessions \\
$\vartheta=14, \alpha=0.41$ & $\pi=0.483$ & $\pi=0.748$ & $\pi=0.483$ and $\pi=0.748$ & 76 participants \\
\hline
\end{tabular}

and SYM, the sharing rule used to divide the benefits from joint production is exogenously fixed. We will refer to these two treatments as fixed contracts. ASYM and SYM represent situations with power balance and imbalance respectively. In FLEX participants choose between a symmetric and an asymmetric contract. If, in FLEX, both participants choose the same sharing rule then this rule is adopted. In case of disagreement the asymmetric rule ASYM is used as the default rule. The FLEX treatment allows us to analyse whether participants want to switch from an asymmetric to a symmetric power structure.

At the beginning of each session we decided randomly whether participants would first play 10 rounds of ASYM and then 10 rounds of SYM (this happened in 7 sessions), or whether to follow the opposite sequence (this happened in 9 sessions). After 10 rounds of SYM and 10 rounds of ASYM participants played 10 rounds of FLEX 4 Participants were rematched randomly after each round. Although different parameters $(\vartheta$ and $\alpha$ ) and sharing rules are employed in conflict and no conflict, equilibrium predictions for the two configurations differ mainly in the flexible contract treatment. With the conflict-parameters there is a conflict of interest between the two players: in FLEX-C the selfish $A$-players prefer the asymmetric contract while $B$-players prefer the symmetric contract. With the no conflict-parameters this is not the case: in FLEX-NC both types of players, $A$ and $B$, prefer the symmetric contract. We will explain this in more detail when illustrating this treatment. When discussing asymmetric contracts, we will refer to type $A$ players as strong and to type $B$ players as weak. We now turn to a more detailed description of the experiment.

\subsection{Fixed Contracts}

In each treatment, players simultaneously invest into joint production. We use tables to represent payoff functions. Table 2 presents an example of a decision screen in the experiment. Players can choose from eleven possible investment levels (multiples of 50 from 0 to 500) which are shown as consecutive numbers ( 1 to 11 ) in the table. Payoffs in the experiment are rounded to integers. In each round of the experiment players are asked to click on a row they might want to choose (their own investment) and on a column they think their opponents might select (the other player's investment). These rows and columns and their intersection are then highlighted on the computer screen. Participants can experiment by clicking on rows and columns as often as they want until they are satisfied with their choices and expectations. Only when a participant clicks on an "OK" button she proceeds to the result stage of the round. This feature not only allows us to check for the consistency of players' expectations and behaviour, but it also promotes a more thoughtful decision-making process.

Discretising a continuous problem and presenting it with the help of payoff tables has both advantages and disadvantages. Key advantages are that the payoff function is easy to understand, that players do not have to calculate anything, and that we can elicit players' expectations in a natural way.

The disadvantage of discretising a continuous problem is that it quickly leads to a large number of equilibria. If we want to have a clear equilibrium prediction, and still present payoffs as tables,

\footnotetext{
${ }^{4}$ In one session of the experiment we played 12 and not 10 rounds of each contract.
} 
Table 2 An example of a decision screen in the experiment

\begin{tabular}{|c|c|c|c|c|c|c|c|c|c|c|c|}
\hline \multicolumn{12}{|c|}{ expected choice of the other player } \\
\hline & 1 & 2 & 3 & 4 & 5 & 6 & 7 & 8 & 9 & 10 & 11 \\
\hline 1 & $\mathbf{5 0 0}^{500}$ & $\mathbf{5 0 0}^{450}$ & $\mathbf{5 0 0}^{400}$ & $\mathbf{5 0 0}^{350}$ & $\mathbf{5 0 0}^{300}$ & $\mathbf{5 0 0}^{250}$ & $\mathbf{5 0 0}^{200}$ & $\mathbf{5 0 0}^{150}$ & $500^{100}$ & $\mathbf{5 0 0}^{50}$ & $500^{\circ}$ \\
\hline 2 & $\mathbf{4 5 0}^{500}$ & $742^{570}$ & $\mathbf{8 2 4}^{554}$ & $\mathbf{8 8 3}^{528}$ & $9^{498}$ & $9^{464}$ & $1005^{429}$ & $1036^{392}$ & $1065^{354}$ & $1092^{315}$ & $1117^{275}$ \\
\hline 3 & $400^{500}$ & $774^{604}$ & $\mathbf{8 8 0}^{598}$ & $955^{579}$ & $1015^{554}$ & $1067^{52}$ & $1112^{494}$ & 1102 & & $\lambda_{223^{390}}$ & $1255^{353}$ \\
\hline 4 & $\mathbf{3 5 0}^{500}$ & $783^{628}$ & $905^{629}$ & $992^{615}$ & $1062^{594}$ & $1121^{56}$ & $1173^{540}$ & $1220^{509}$ & $1263^{47}$ & $1302^{443}$ & $1339^{408}$ \\
\hline $\begin{array}{l}\frac{0}{0} \\
\frac{1}{0}\end{array}$ & $\mathbf{3 0 0}^{500}$ & $780^{648}$ & $915^{654}$ & $1012^{644}$ & $1089^{625}$ & $1155^{60}$ & $1213^{576}$ & $1265^{548}$ & $1312^{517}$ & $\mathbf{1 3 5 6}^{485}$ & $1397^{432}$ \\
\hline ईa & $\mathbf{2 5 0}^{500}$ & $770^{664}$ & $917^{675}$ & $1021^{66}$ & $1105^{653}$ & $1176^{632}$ & $1239^{608}$ & $1295^{58}$ & $1347^{552}$ & $1394^{522}$ & $1438^{490}$ \\
\hline $\bar{\partial}$ & $\mathbf{2 0 0}^{500}$ & $755^{679}$ & $912^{694}$ & $1023^{690}$ & $1113^{676}$ & $1189^{658}$ & $1256^{635}$ & $1316^{610}$ & $1371^{583}$ & $1421^{554}$ & $1468^{523}$ \\
\hline 8 & $150^{500}$ & $736^{692}$ & $902^{710}$ & $1020^{709}$ & $1115^{698}$ & $1195^{681}$ & $1266^{660}$ & $1329^{636}$ & $1387^{610}$ & $1441^{582}$ & $1490^{553}$ \\
\hline 9 & $100^{500}$ & $715^{704}$ & $\mathbf{8 8 9}^{725}$ & $1013^{726}$ & $1112^{717}$ & $1197^{70}$ & $1271^{683}$ & $1337^{66}$ & $1398^{635}$ & $1454^{608}$ & $1506^{580}$ \\
\hline 10 & $\mathbf{5 0}^{500}$ & $692^{71}$ & $873^{74}$ & $1002^{743}$ & $1106^{735}$ & $1194^{72}$ & $1271^{704}$ & $1341^{6}$ & $1404^{65}$ & $1463^{633}$ & 1517 \\
\hline 1 & $0^{500}$ & $667^{7}$ & $855^{7}$ & $\mathbf{9 8 9}^{758}$ & $1097^{7}$ & $1188^{7}$ & $1268^{723}$ & $1340^{7}$ & $1406^{68}$ & $1467^{655}$ & 1524 \\
\hline
\end{tabular}

In this example a participant has clicked on " 3 " in the left column to indicate her own choice. As a result the corresponding row is shown in red. She has also clicked on " 9 " in the top row to indicate her expectations about the choice of the other player. As a result this column is shown in red and the intersecting pair of payoffs is highlighted with a blue circle. The participant can now click on the OK-button to continue to the next stage. She can also wait and adjust her choices and expectations. Own payoffs are shown in boldface in the bottom left part of each cell of the table, the other payoffs are shown in a smaller font in the top right part.

\section{Figure 1 Best reply functions}

$$
\mathrm{A} \circ-\mathrm{B}+---
$$

$\begin{array}{llllllllll}2 & 4 & 6 & 8 & 10 & 2 & 4 & 6 & 8 & 10\end{array}$

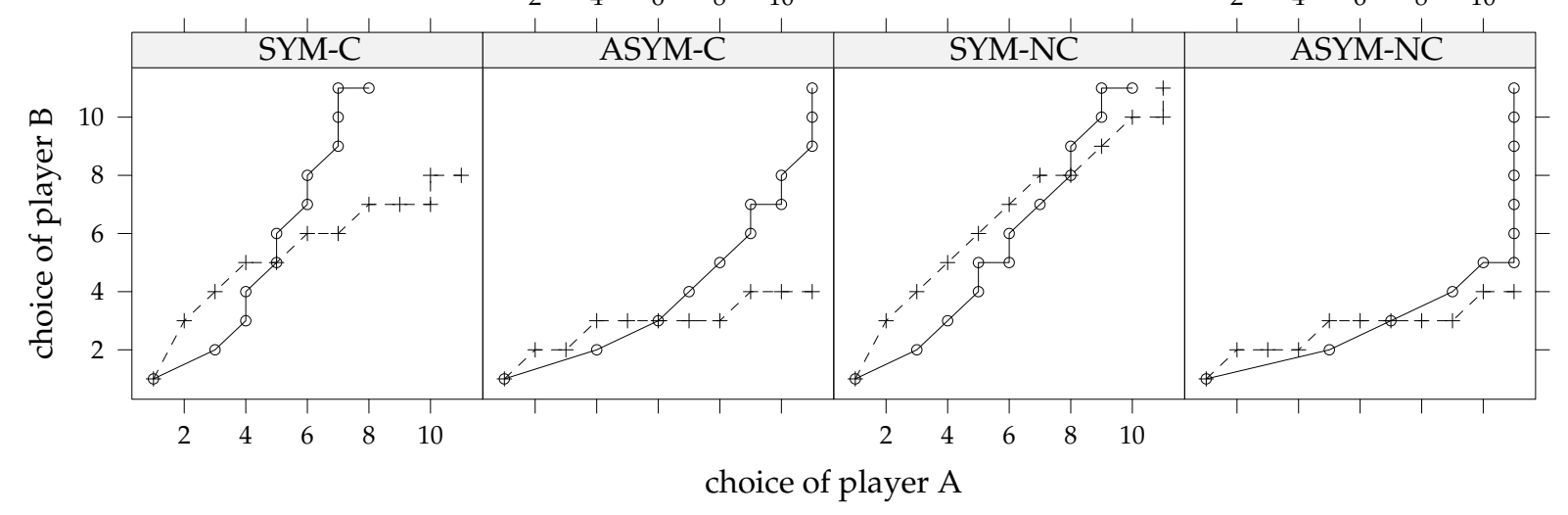

then we have to live with a parameter space that is considerably restricted. In particular, we can only use values of $\pi$ which are bounded away from $1 / 2$. Hence, when we call a sharing rule "symmetric" then this is only an approximation: $\pi=0.491$ and $\pi=0.483$ are as close as we can get to $1 / 2$. Under symmetric sharing rules ( $\pi^{\text {SYM }}$ is 0.491 or 0.483$)$ each player is entitled to an almost equal share of the total monetary output. Under asymmetric sharing rules ( $\pi^{\mathrm{ASYM}}$ is 0.708 or 0.748 ) the strong player $A$ receives a substantially larger portion of the total output than the weak player $B$. The parameter values for $\vartheta$ and $\alpha$ are given in Table $1, M_{i}$ is always 500 .

We illustrate the best reply functions for ASYM and SYM, under either conflict (C) or no conflict (NC), in Figure 1, assuming that individuals are motivated purely by self-interest. For each situation there is an interior Nash equilibrium in which both players invest part of their endowment 


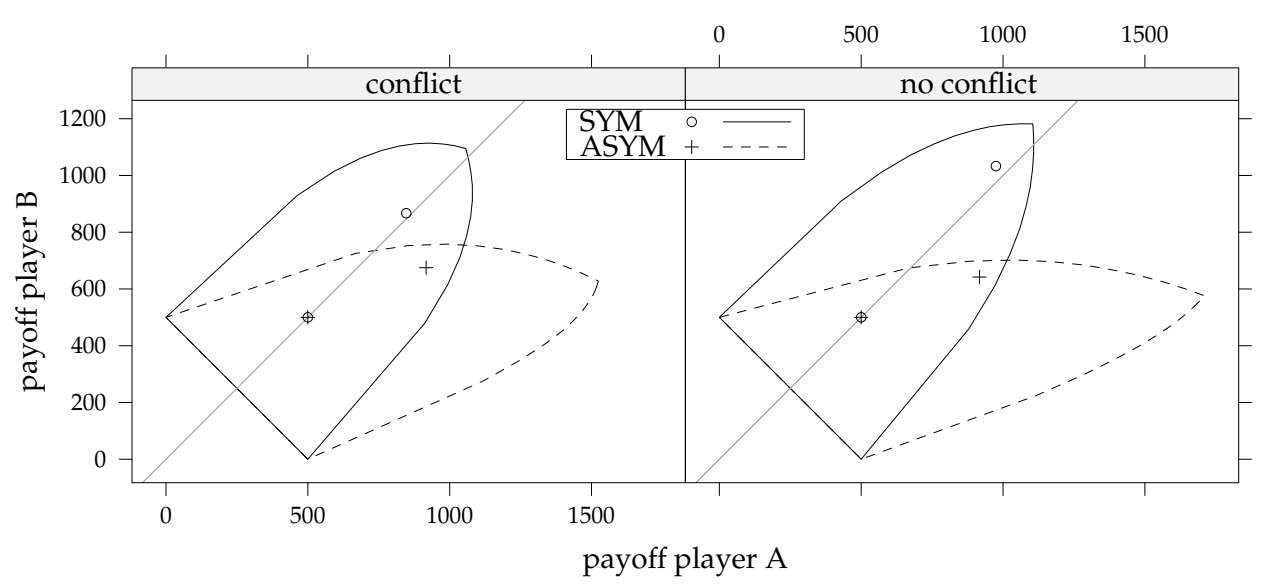

Lines show the convex hull of payoff possibilities for the different situations. Points denote equilibrium payoffs. The thin gray line is the $45^{\circ}$ line.

into joint production; there is also an equilibrium in which both players invest zero. The first best, which is equivalent to the maximum possible investment, is not an equilibrium under any sharing rule. Intuitively, this is because players do not capture the full marginal returns on their investments. As a consequence, equilibrium investment levels are inefficiently low. However, some sharing rules provide better investment incentives than others. In particular, if participants in the experiment are motivated by self-interest and select interior equilibria, then asymmetric sharing rules lead to lower aggregate payoffs than symmetric sharing rules.$^{5}$

We now turn our attention to payoff distributions. If players follow standard equilibrium predictions and select interior equilibria, then asymmetric sharing rules not only imply lower aggregate investments, but also unequal payoff distributions. Figure 2 shows the convex hull of the feasible payoff pairs for both treatments, under either conflict or no conflict. The dashed line marks the payoff combinations that can be obtained with the asymmetric sharing rule. The solid line shows the payoff combinations that can be achieved with symmetric sharing rules. Equilibrium payoff pairs under asymmetric sharing rules are marked with a " + ", while those under symmetric sharing rules are marked with a " $\circ$ ". If players choose interior equilibria then ASYM sharing rules give rise to rather large payoff differences. The interior equilibrium payoffs of type $A$ players exceed those of type $B$ players by about $36 \%$ in conflict and $43 \%$ in no conflict. For the sharing rules that we call SYM there is still a deviation, but it is much smaller: $2 \%$ in conflict and $6 \%$ in no conflict.

\subsection{Flexible Contracts}

After having played the fixed contract game with 10 rounds of SYM and 10 rounds of ASYM sharing rules, in FLEX players can choose between ASYM and SYM. They see both payoff matrices on their screen and make choices for both situations but they also indicate a preference for one of the two matrices, i.e. for one of the two sharing rules. The default rule is always ASYM. If both players prefer the same contract (either SYM or ASYM), then this contract is implemented; if players disagree, then the status quo contract ASYM is used. We use the strategy method and ask players in each period whether they prefer SYM or ASYM and, simultaneously, which investment

\footnotetext{
${ }^{5}$ Theoretically, if players simultaneously choose $I_{A}$ and $I_{B}$ to respectively maximise $M_{A}-I_{A}+\pi \cdot\left(I_{A} I_{B}\right)^{\alpha} \vartheta$ and $M_{B}-I_{B}+(1-\pi) \cdot\left(I_{A} I_{B}\right)^{\alpha} \vartheta$, then the sharing rule that maximises joint payoffs is given by $\pi^{*}=1 / 2$.
} 
they would choose under ASYM and under SYM. When both players have made their choice we reveal the chosen contract, investments and payoffs.

Which contracts should players choose? In Figure 2 we notice that in both configurations, conflict and no conflict, a weak (B) player prefers SYM over ASYM in equilibrium. Intuitively, this is because both total investments and the weak player's share increase from ASYM to SYM. For the strong $(A)$ player the situation is different: On the one hand, an agreement to implement a more equitable sharing rule reduces a strong $(A)$ player's share of the total surplus ("surplus division effect"). On the other hand, such an agreement induces the weak $(B)$ player to invest more into joint production ("investment effect"). Under conflict, the surplus division effect dominates the investment effect, and so it is rational for a strong $(A)$ player to veto the implementation of a more equitable sharing rule. Under no conflict, the investment effect dominates the surplus division effect, and hence it is rational for a strong $(A)$ player to give up her power in favour of a symmetric sharing rule.

\section{Behavioural Predictions}

\subsection{Preferences}

Our discussion and predictions so far are based on the assumption of common knowledge of rationality and selfishness of all players. However, experimental evidence suggests that not all individuals simply maximise monetary payoffs. Two features of our basic model make it conceivable that behavioural motives might enter players' investment decisions: the allocation under standard equilibrium predictions is inefficient and unequal. Players might therefore be concerned about social efficiency or reveal an aversion towards inequality. In this section we will show that these different types of social preferences imply quite different patterns of investment behaviour.

To generate behavioural predictions we follow a model of social preferences as proposed by Charness and Rabin (2002). Letting

$$
U_{A}\left(I_{A}, I_{B}\right)=M-I_{A}+\pi \cdot\left(I_{A} I_{B}\right)^{\alpha} \vartheta \quad \text { and } \quad U_{B}\left(I_{A}, I_{B}\right)=M-I_{B}+(1-\pi) \cdot\left(I_{A} I_{B}\right)^{\alpha} \vartheta
$$

denote player $A$ 's and $B$ 's monetary payoffs, we suppose that players' preferences are given by:

$$
V_{A}\left(I_{A}, I_{B}\right)=(\rho \cdot r+\sigma \cdot s) \cdot U_{B}\left(I_{A}, I_{B}\right)+(1-\rho \cdot r-\sigma \cdot s) \cdot U_{A}\left(I_{A}, I_{B}\right)
$$

and

$$
V_{B}\left(I_{A}, I_{B}\right)=(\rho \cdot s+\sigma \cdot r) \cdot U_{A}\left(I_{A}, I_{B}\right)+(1-\rho \cdot s-\sigma \cdot r) \cdot U_{B}\left(I_{A}, I_{B}\right)
$$

where $r=1$ and $s=0$ if $U_{A}(\cdot)>U_{B}(\cdot), r=0$ and $s=1$ if $U_{A}(\cdot)<U_{B}(\cdot)$, and $r=0$ and $s=0$ if $U_{A}(\cdot)=U_{B}(\cdot)$. This is basically the model of Charness and Rabin (2002), except that, in this simultaneous move game, we leave out the term for reciprocity. The parameters $\rho$ and $\sigma$ allow for a range of different "distributional preferences". We distinguish here "competitive preferences", "inequality-averse preferences" and "social-welfare preferences" (see Figure 3).

Competitive preferences correspond to $\sigma \leq \rho \leq 0$, meaning that each player prefers to do as well as possible in comparison to her opponent, while also caring directly about her own payoff. Models of inequity (difference) aversion (Fehr and Schmidt, 1999; Bolton and Ockenfels, 2000) assume that people prefer to minimise disparities between their own payoffs and those of other people. Inequity aversion corresponds to $\sigma<-\rho<0$. That is, people suffer utility losses from both disadvantageous and advantageous payoff disparities, but suffer more from disparities that are to their disadvantage. By contrast, the notion of social-welfare preferences captures the idea that individuals prefer higher payoffs for themselves and for other persons, but are more concerned about own payoffs when they are disadvantaged compared to others (Charness and 


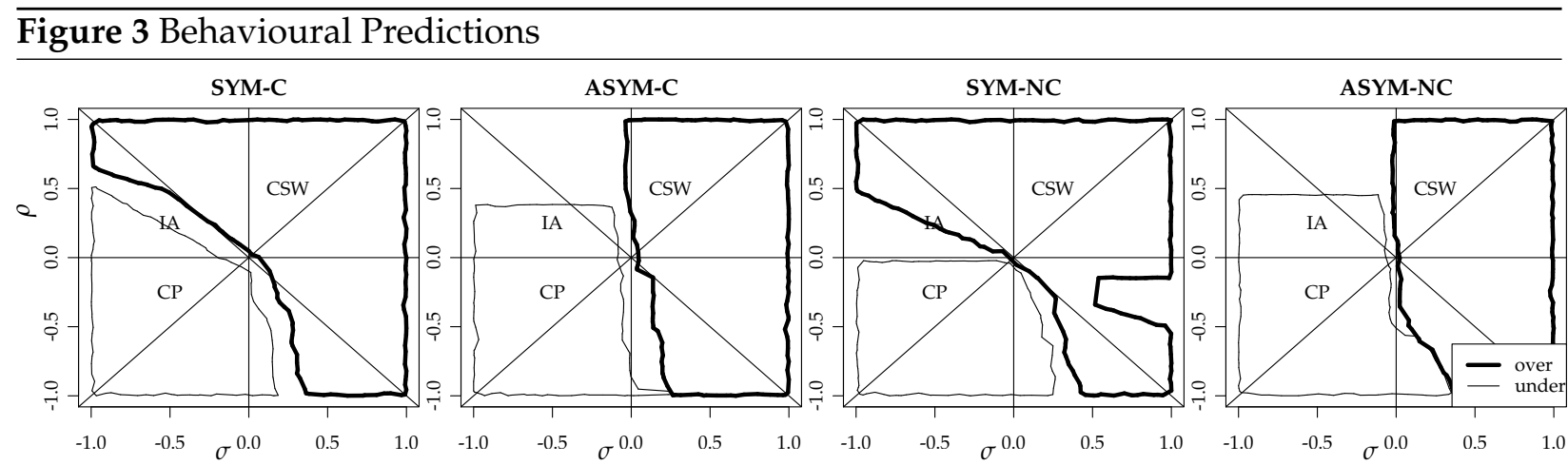

The orthants marked IA, CSW, and CP denote IA=inequity aversion; CSW=concern for social welfare; $\mathrm{CP}=$ competitive preferences. The regions are $\alpha$-convex hulls $(\alpha=0.1)$ of the result of a Monte Carlo simulation with 10000 random combinations of $\sigma$ and $\rho$ where $\sigma$ and $\rho$ are uniformly distributed over $(-1,1)$. The thick line surrounds the range of $\sigma$ and $\rho$ where in the most efficient equilibrium both players invest more than in the most efficient selfish equilibrium. The thin line surrounds the range of $\rho$ and $\sigma$ where both players invest less.

Rabin, 2002). Concerns for social-welfare can be represented by assuming that $1>\rho>\sigma>0$.

\subsection{Investments}

The question we are now considering is the extent to which different forms of social preferences may explain behavioural deviations from standard Nash predictions. For the sake of simplicity, we focus on only two hypothetical deviations. In the first, both players invest strictly more than what selfish players would invest in equilibrium. In the second, both players invest strictly less than in the self-interest benchmark. Figure 3 shows the regions for $\sigma$ and $\rho$ where both $A$ and $B$ either invest strictly less than the selfish equilibrium or strictly more than the selfish equilibrium. In the figure we show results of a Monte Carlo simulation based on our discretised version of the game. A detailed derivation of behavioural predictions in the context of the continuous model can be found in our working paper, Faravelli et al. (2010). The key insight that one may extract from Figure 3 is the following:

- In all four situations, an outcome in which both players invest strictly more compared to the self-interest benchmark is consistent with concerns for social welfare $(1 \geq \rho \geq \sigma>0) b^{6}$

- Conversely, an outcome in which both players invest strictly less compared to the selfinterest benchmark is consistent with either competitive preferences $(\sigma \leq \rho \leq 0)$ or preferences to minimise differences in payoffs $(\sigma<-\rho<0)$.

Thus, the message here is that the impact of social motives on investment incentives depends on the specific type of social preferences that people exhibit. Concerns for social welfare will mitigate the underinvestment problem created by incomplete contracts. Inequity aversion or competitive preferences will exacerbate the underinvestment problem. The latter point holds particularly true for partnerships in which the rights to returns from production are allocated asymmetrically. In what follows, we will use these results to guide our way of interpreting the data from our experiment.

\subsection{Voting for contracts}

In the third part of the experiment, the FLEX treatment, players can vote for their preferred contract. In a world where players are selfish the (weaker) $B$ player always prefers the SYM contract. In the no conflict configuration also the $A$ player prefers the SYM contract. However, in the conflict

\footnotetext{
${ }^{6}$ We should note that for the symmetric treatments overinvestment can also be consistent with inequality aversion. However, below we will find overinvestment also for the asymmetric treatments.
} 


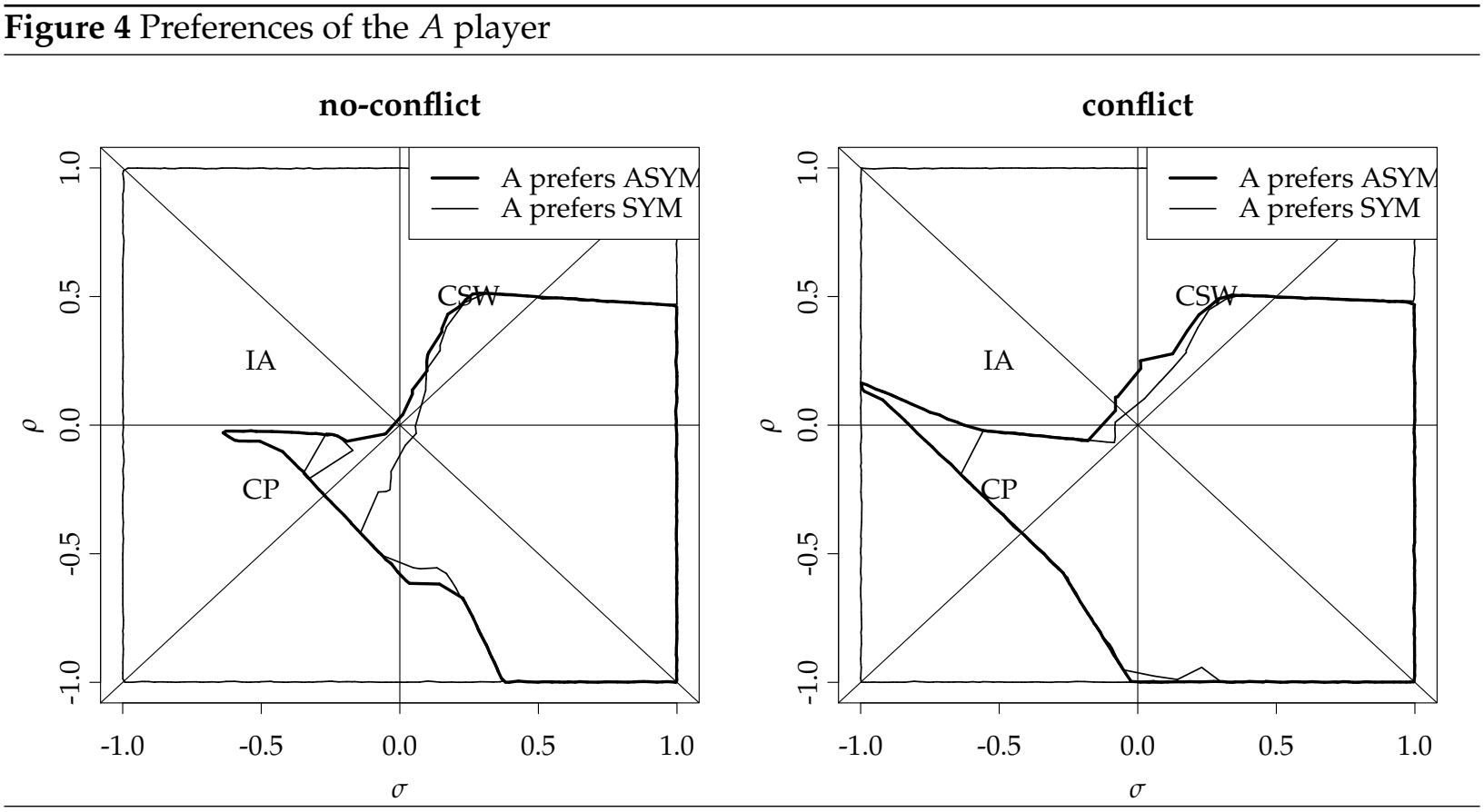

configuration the A player would prefer the ASYM contract. Things change when players have social preferences. For which preferences $(\sigma, \rho)$ do both participants vote for the fair contract? To answer this question we draw for each configuration in the experiment 100000 random combinations of $\sigma$ and $\rho$ where $\sigma$ and $\rho$ are uniformly distributed over $(-1,1)$. If there are several equilibria, we assume that players play the most efficient one. For each combination of $\sigma$ and $\rho$ we determine the preferences of the $A$ player.

Figure 4 shows the $\alpha$-convex hull of the regions (with $\alpha=0.1$ ) where $A$ prefers ASYM and SYM, respectively. Although the two regions overlap to some degree, they are sufficiently distinct. In a world where players are inequality averse we should always observe the SYM contract in the no conflict configuration, and almost always in the conflict configuration.

Things are less clear in a world where players have concerns for social welfare. If these concerns are mainly driven by the stonger player ( $\rho$ is large and $\sigma$ is small) then we should observe the SYM contract. However, if concerns for social welfare are also driven by the weak player ( $\sigma$ is relatively large) then the $A$ player would still prefer the ASYM contract. Knowing that players have concerns for social welfare alone is, hence, not sufficient to decide what contracts they will choose in equilibrium.

\section{Results}

\subsection{Expectations and Behaviour with Fixed Contracts}

Figures 5 and 6 show the distribution of choices and expectations for ASYM-C and SYM-C respectively. Sizes of circles are proportional to frequencies. The figures also include the best reply functions as already shown in Figure $\left.1\right|^{7}$

The left hand graph in Figure 5 shows choices and expectations of type $A$ players, i.e. players who get a share of $\pi=0.708$. Only $8 \%$ of these players expect Nash investments of their opponents. The majority, $89.4 \%$, expect their opponent to invest more than the Nash equilibrium. But

\footnotetext{
${ }^{7}$ As best reply functions are closer to each other under no conflict, the relative figures are less instructive and we do not show them for the sake of brevity
} 


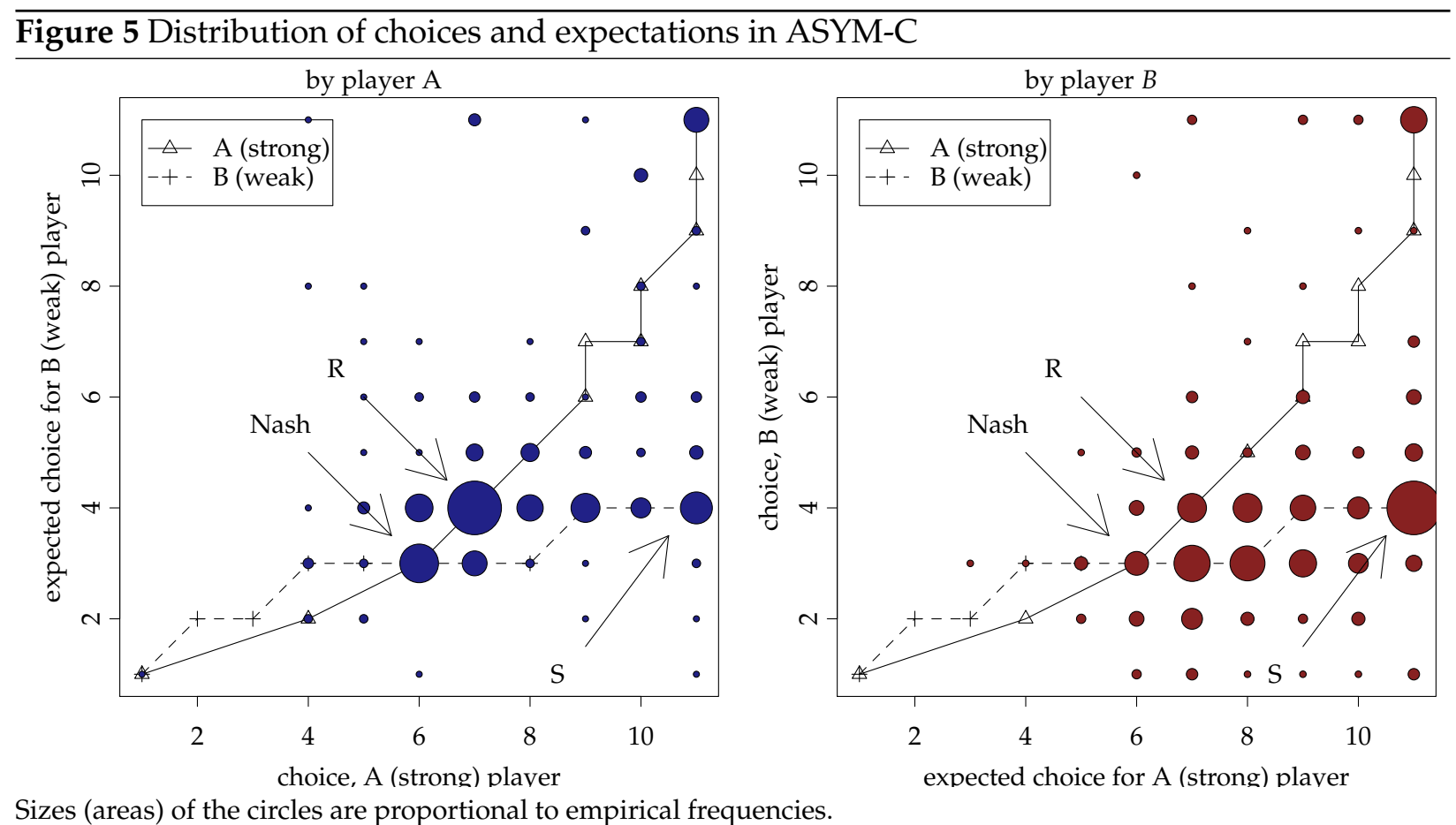

not only expectations are optimistic, $A$ players also invest a lot: $36.9 \%$ invest more than the best reply to their expectations and $44.6 \%$ play a best reply to their expectations. Only $18.6 \%$ invest less than their best reply. It is this combination of positive expectations and overinvestment that leads in the end $74.9 \%$ of all $A$ players to invest more than the selfish equilibrium levels $(19.1 \%$ invest Nash equilibrium levels).

The right hand graph in Figure 5 shows choices and expectations of type $B$ players. In line with the choices of player $A$ the majority, $89.4 \%$, expect their opponent to invest more than the selfish equilibrium. $32 \%$ invest more than the best reply and $48 \%$ play a best reply to their expectations. Only 20\% invest less than their best reply. In the end 58\% of all $B$ players invest more than Nash equilibrium levels (31.1\% invest Nash equilibrium levels).

It is interesting to note that these expectations, and subsequent choices, are consistent with the equilibrium prediction when players display concerns for social welfare. $A$ players invest well above the self-interest Nash equilibrium level, and expect a small amount of overinvestment from their weak opponents. On the other hand, weak players expect their opponents to choose investments above the self-interest Nash equilibrium, and reply by overinvesting a small amount, although not as much as their opponents.

Figure 6 shows choices and expectations for the symmetric contract. We can see that a large part of players expect their opponents to invest more than Nash equilibrium and best reply accordingly by also investing more. As in the asymmetric case, this pattern is also consistent with the hypothesis that individuals display social welfare preferences.

To provide a more formal analysis of the behavioural patterns observed in Figures 5 and 6 we estimate the following equation

$$
\bar{I}_{i j}-I_{i}^{N}=\beta_{1}+\beta^{\mathrm{SYM}} \cdot d_{i j}^{\mathrm{SYM}}+\beta^{\text {strong }} \cdot d_{i j}^{\text {strong }}+u_{s}+u_{i}+u_{i j}
$$

where $I_{i j}$ is the investment of player $i$ in period $j$ during a given treatment (either SYM or ASYM) and $I^{N}$ is the Nash equilibrium investment level. The dummy variable $d_{i j}^{\text {SYM }}$ is one for symmetric power sharing and zero otherwise, $d_{i j}^{\text {strong }}$ is one for the strong player (A) under asymmetric 


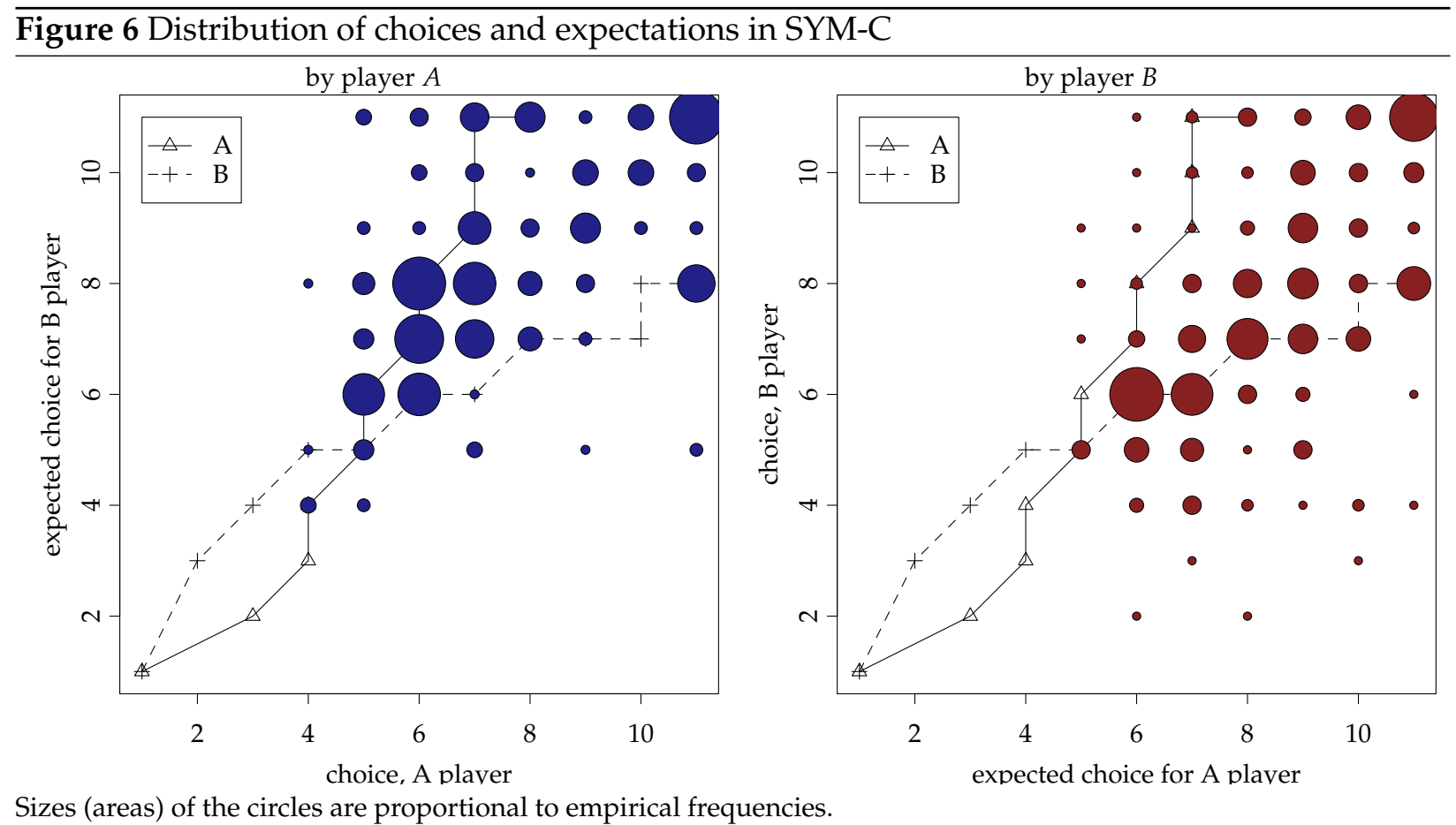

Table 3 Mixed effects estimation of equation 4 for no conflict

\begin{tabular}{l||c|c|c|c|cc|}
\hline & $\beta$ & $\sigma$ & $t$ & $p$ value & $95 \%$ conf & interval \\
\hline 1 & 0.712 & 0.243 & 2.93 & 0.0034 & 0.236 & 1.19 \\
$d^{\text {SYM }}$ & 1.71 & 0.0861 & 19.8 & 0.0000 & 1.54 & 1.88 \\
$d^{\text {strong }}$ & 0.93 & 0.119 & 7.83 & 0.0000 & 0.697 & 1.16 \\
\hline
\end{tabular}

sharing rules and zero otherwise. Sessions are indexed with $s$, players are indexed with $i$, and different periods have the index $j$. Throughout the paper and unless specified otherwise we estimate mixed effects models with random effects for the matching group $u_{s}$ and for the participant $u_{i}$ where we assume that error terms $u_{s}, u_{i}$ and $u_{i j}$ follow a normal distribution with mean zero. For the linear models standard deviations, $p$ values and confidence intervals are based on a bootstrap with 10000 replications. We estimate equation (4) separately for conflict and no conflict. Estimation results are shown in Tables 3 and 4 .

\section{Result 1}

(a) Players' expectations of their partners' choices are generally consistent with the actual investments undertaken.

(b) Under both symmetric and asymmetric sharing rules, strong $(A)$ and weak (B) players overinvest on average $\left(\beta_{1}>0, \beta^{\text {strong }}>0, \beta^{S Y M}>0\right.$ in Tables 3 and 4 .

(c) With SYM, players invest more than with ASYM $\left(\beta^{S Y M}>0\right)$.

(d) Strong (A) players invest more than weak (B) players ( $\beta^{\text {strong }}>0$ ).

\subsection{Behavioural motives}

The above discussion indicates that players' investments deviate from equilibrium investments of selfish players. We now check whether distributional preferences can explain our observations. 


\begin{tabular}{l||c|c|c|c|cc|}
\hline Table 4 Mixed effects estimation of equation 4 for conflict \\
\hline & \multicolumn{1}{c||}{$|c| c|c| c|c| c|c|$} & \\
\hline 1 & 0.302 & 0.182 & 1.66 & 0.0971 & -0.0548 & 0.659 \\
$d^{\text {SYM }}$ & 1.19 & 0.0603 & 19.7 & 0.0000 & 1.07 & 1.31 \\
$d^{\text {strong }}$ & 1.96 & 0.0831 & 23.6 & 0.0000 & 1.8 & 2.13 \\
\hline
\end{tabular}

Table 5 Frequencies of choices

\begin{tabular}{|c|c|c|c|c|c|c|c|c|}
\hline \multirow{2}{*}{\multicolumn{4}{|c|}{ no conflict }} & \multicolumn{5}{|c|}{ conflict } \\
\hline & & & & \multicolumn{2}{|c|}{ ASYM-C } & \multicolumn{3}{|c|}{ player A } \\
\hline \multirow{4}{*}{$\begin{array}{l}\infty \\
\dot{\varpi} \\
\stackrel{\vec{\sigma}}{0} \\
\frac{1}{2}\end{array}$} & $<$ & $=$ & $>$ & \multirow{4}{*}{$\sum_{\frac{\pi}{d}}^{\infty}$} & & $<$ & $=$ & $>$ \\
\hline & 1 & 6 & 31 & & $<$ & 1 & 6 & 29 \\
\hline & 7 & 32 & 70 & & $=$ & 4 & 15 & 82 \\
\hline & 13 & 29 & 161 & & $>$ & 9 & 29 & 213 \\
\hline SYM-NC & \multicolumn{3}{|c|}{ player A } & \multirow{2}{*}{\multicolumn{2}{|c|}{ SYM-C }} & & yer & \\
\hline \multirow{4}{*}{$\begin{array}{l}n \\
\dot{d} \\
\frac{\vec{\sigma}}{2} \\
\frac{1}{2}\end{array}$} & $<$ & $=$ & $>$ & & & $<$ & $=$ & $>$ \\
\hline & 0 & 3 & 15 & \multirow{3}{*}{ 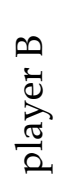 } & $<$ & 3 & 4 & 18 \\
\hline & 1 & 4 & 23 & & $=$ & 6 & 7 & 23 \\
\hline & 4 & 37 & 263 & & $>$ & 27 & 70 & 230 \\
\hline
\end{tabular}

The tables show for the different situations the frequency of pairs of choices where players' investments were smaller $(<)$, equal $(=)$, or larger $(>)$ than Nash equilibrium investments.

More precisely, in light of the predictions we formulated in Section 4 , we want to explore whether players' behaviour is consistent with either inequity aversion, social welfare or competitive preferences. Table 5 shows frequencies of pairs of investments that were smaller, equal or larger than Nash equilibrium. We see that in all cases the majority of pairs simultaneously invests more than Nash equilibrium.

Recall from the discussion in section 4 that a pair of inequity averse players would not choose to invest more than in the self-interest benchmark under ASYM. The observed behaviour is consistent not with inequity aversion but with concerns for social welfare.

Result 2 Players' behaviour is consistent with social welfare preferences, while it cannot be explained by either inequality aversion or competitive preferences.

\subsection{Inequality}

Since most players invest more than in the self-interest benchmark social welfare is larger than in the selfish equilibrium. Interestingly, this comes with an increase in inequality. Figure 7 shows the distribution of payoffs for the weak and for the strong player in ASYM. Sizes of the circles are proportional to empirical frequencies. We clearly see that the actual allocations are typically more efficient than Nash equilibrium allocations. However, they are often even more unequal than the (already unequal) Nash equilibrium allocation. For the ASYM treatments inequality in the experiment (measured as payoff ratio) is $5.4 \%$ larger on average than inequality under the Nash equilibrium. 8 These results do support the general findings outlined in Charness and Rabin (2002).

Result 3 When asymmetric sharing rules are employed, payoff allocations are typically more efficient, but more unequal than the self-interest equilibrium allocation.

\footnotetext{
${ }^{8}$ This is significantly different from zero with a $p$-value of $3.7 \%$.
} 


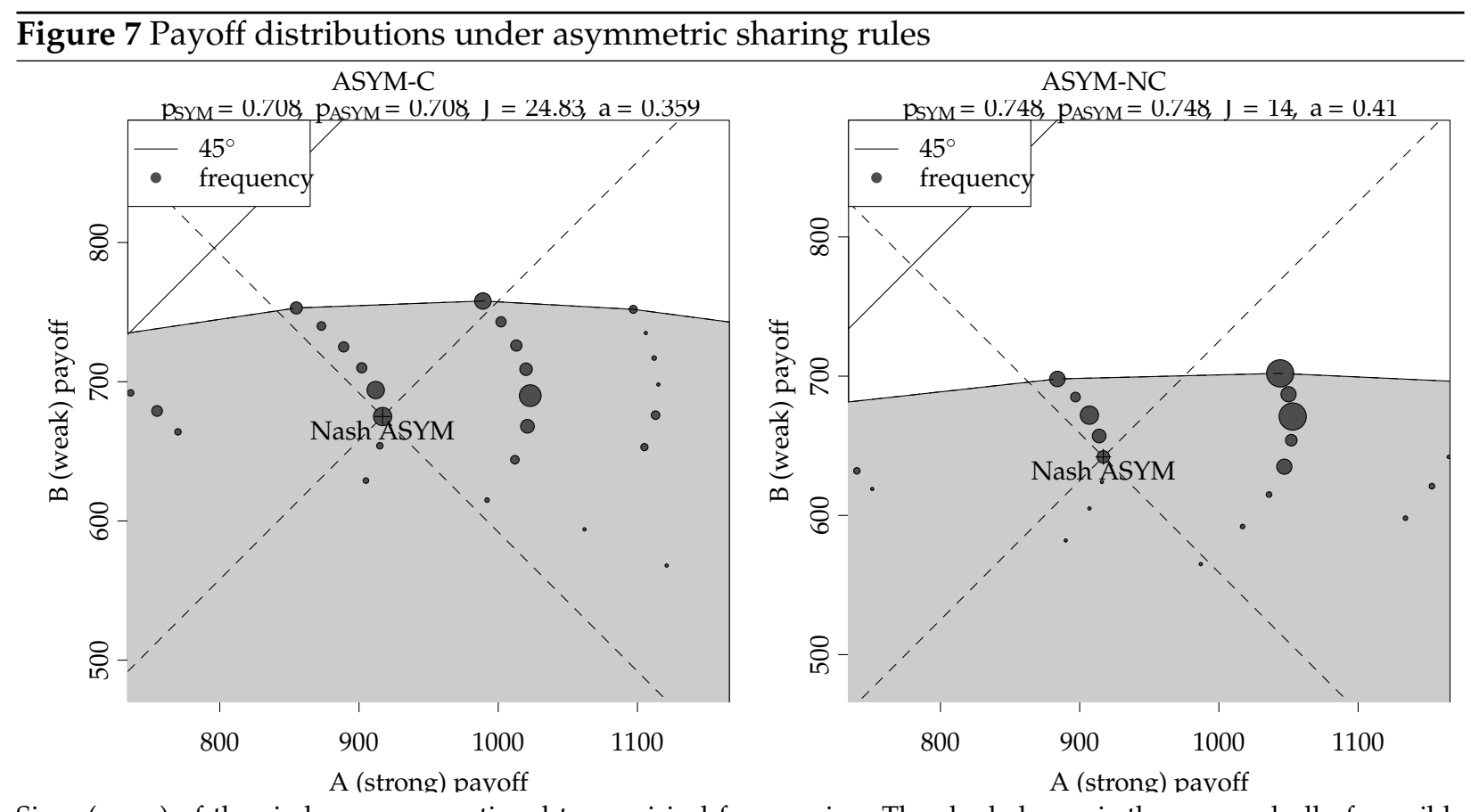

Sizes (areas) of the circles are proportional to empirical frequencies. The shaded area is the convex hull of possible payoffs.

\subsection{Flexible contracts}

The last part of the experiment is the situation FLEX where players can choose what kind of sharing rule to adopt. $B$ players, who in equilibrium benefit from the symmetric contract, almost always vote in favour of the symmetric sharing rule ( $98 \%$ of all cases in FLEX-C and in $98.2 \%$ of all cases in FLEX-NC. A players benefit (in the equilibrium of a selfish world) from the symmetric contract only in FLEX-NC. Indeed, in this situation they vote for the symmetric contract in $80.6 \%$ of all cases. Although in FLEX-C A players would (in the equilibrium of a selfish world) not benefit from the symmetric contract, they still vote for this contract in $39.4 \%$ of all cases.

Result 4 (a) Weak players (B) almost always vote in favour of symmetric sharing rules.

(b) In FLEX-NC most strong players (A) agree to share power.

(c) In FLEX-C fewer, but still a substantial proportion of the strong players ( $A$ ) agrees to share power.

The first observation is what we should expect, irrespective of the social preferences of the $B$ players. The second observation suggests that if $A$ players have concerns for social welfare, then, as we have seen in section 4.3 , these concerns are mainly driven by the stronger person, i.e. $\rho$ is relatively large and $\sigma$ is relatively small.

Reasons to vote for the symmetric contract Let us try to understand better why in the FLEX-C situation $A$ players do vote for the symmetric contract. This might be the result of (direct) other regarding preferences, but also the result of their good experience with SYM (which can be seen as an indirect effect of other regarding preferences earlier in the game). We will start with the second reason and then come to (direct) other regarding preferences below.

Recall that before playing FLEX, players had experienced both 10 rounds of SYM and 10 rounds of ASYM. In the no conflict configuration A players should theoretically expect higher payoffs with SYM than with ASYM. Indeed, this is the case for $76 \%$ of all $A$ players. In the conflict configuation 


\begin{tabular}{l||c|c|c|c|cc|}
\hline Table 6 Mixed effects estimation of equation 5 & for player $A$ \\
\hline & $\beta$ & $\beta$ & $z$ & $p$ value & $95 \%$ conf & interval \\
\hline 1 & -4.7 & 2.32 & -2.03 & 0.0424 & -9.25 & -0.16 \\
$r$ & 5.8 & 2.2 & 2.64 & 0.0083 & 1.49 & 10.1 \\
$d^{\text {confl. }}$ & -1.45 & 0.463 & -3.13 & 0.0018 & -2.36 & -0.54 \\
\hline
\end{tabular}

Table 7 Mixed effects estimation of equation 6 for player A, conflict

\begin{tabular}{l||c|c|c|c|cc|}
\hline & $\beta$ & $\sigma$ & $t$ & $p$ value & $95 \%$ conf & interval \\
\hline 1 & 2.23 & 0.304 & 7.33 & 0.0000 & 1.63 & 2.82 \\
$d^{\text {SYMvote }}$ & -0.47 & 0.162 & -2.91 & 0.0038 & -0.788 & -0.153 \\
$d^{\text {SYM }}$ & -1.26 & 0.173 & -7.28 & 0.0000 & -1.6 & -0.919 \\
$d^{\text {SYMvote }} \times d^{\text {SYM }}$ & 0.757 & 0.195 & 3.89 & 0.0001 & 0.375 & 1.14 \\
\hline
\end{tabular}

A players should theoretically expect smaller payoffs with SYM than with ASYM (and, hence, vote against). However, $43 \%$ of the $A$ players experienced larger payoffs with SYM than with ASYM. Not surprisingly, many of them then vote for SYM.

These higher payoffs with SYM are not least a consequence of the social welfare preferences exhibited by both players which led to overinvestment under SYM. A players, who made a good experience with SYM in the first part of the game, are likely to vote for SYM when they can. These players are willing to invest more than the rational Nash level and, at the same time, expect to be rewarded by their partners' higher investments. To test this more formally, we estimate a mixed effects probit model.

$$
P\left(\text { SYMvote }_{i j}\right)=\Phi\left(\beta_{1}+\beta^{r} \cdot r_{i}+\beta^{\text {confl. }} \cdot d_{i}^{\text {confl. }}+u_{s}+u_{i}\right)
$$

We call $r_{i}$ the ratio of payoffs $r_{i}=\bar{\pi}_{i}^{\mathrm{SYM}} / \bar{\pi}_{i}^{\mathrm{ASYM}}$ which was experienced in the previous stages of the game. The dummy $d_{i}^{\text {confl. }}$ is one in conflict and zero in no conflict. We include random effects for the matching group $u_{s}$ and for the participant $u_{i} . \Phi$ is the standard normal distribution. Results are shown in table 6 . As we should expect the coefficient of $r_{i}$ is positive and significant: the larger the relative profits under SYM in the first stage of the game are, the higher the probability that an $A$ player votes in the FLEX stage for SYM. Also not surprisingly the coefficient of $d_{i}^{\text {confl. }}$ is negative and significant: the general inclination to vote for SYM is smaller in the conflict configuation.

Votes for symmetry and other regarding preferences We have just seen that even a selfish player might have a reason to vote for a symmetric contract. We will next show that votes for the symmetric contract are also linked to prosocial behaviour. To see this we estimate Equation 6 for the strong player $(A)$ (for the FLEX treatment where players can choose a contract).

$$
\begin{aligned}
I_{i j}-I^{N}= & \beta_{1}+\beta^{\text {SYMvote }} \cdot d_{i j}^{\text {SYMvote }}+\beta^{\text {SYM }} \cdot d_{i j}^{\text {SYM }}+ \\
& +\beta^{\text {SYMvote } \times \mathrm{SYM}} \cdot d_{i j}^{\text {SYMvote }} \cdot d_{i j}^{\text {SYM }}+u_{s}+u_{i}+u_{i j}
\end{aligned}
$$

Again we estimate a mixed effects model with random effects for the matching group $u_{s}$ and for the participant $u_{i}$. Estimation results are shown in Tables 7 and 8 . We must be aware that we can only make a statement on correlations here. Neither do votes directly influence investments nor vice versa. Instead it is the (latent) social preference which affects both. Still, we find a significantly positive coefficient $\beta^{\text {SYMvote } \times S Y M}$ in both tables. This is only mildly interesting in table 8 where we look at a situation where it is in the own interest of the strong players to move to a power sharing 


\begin{tabular}{l} 
Table 8 Mixed effects estimation of equation 6 \\
\hline
\end{tabular}

rule and a vote for SYM does not express other regarding preferences. However, in table 7 power sharing, i.e. a vote for the SYM contract, can be interpreted as a sign other regarding preferences. We should also note that players who vote for SYM contribute less in the ASYM $\left(\beta^{\text {SYMvote }}<0\right)$ where, indeed, a contribution is less efficient. We can take this as another sign of concerns for social welfare.

Result 5 Strong players who vote in favour of SYM show stronger concerns for social welfare than players who vote against.

\section{Conclusion}

The seminal works of Grossman and Hart (1986) and Hart and Moore (1990) have shed light on the central role played by property rights when contracts are incomplete, describing their effect on parties' incentives to undertake relationship-specific investments. Property rights can be looked at as an abstract exemplification of the way power is allocated between parties. Indeed, partnerships can be characterised by their power structure, and it is very common to observe partnerships in which one party holds more power than another. In this paper, we explored experimentally the extent to which different power structures affect incentives to make relationship-specific investments when contracts are incomplete. Despite the great attention devoted to incomplete contracts in recent years, only a limited amount of experimental evidence has been produced so far.

We considered two equally productive players who simultaneously decide how much to invest into a joint production process. We first analysed the players' investment behaviour when the power structure is exogenously imposed. As the players' productivity is the same, theory predicts that total investments would be lower in the presence of power imbalances and higher when power is shared equally. This result is confirmed by our experimental evidence. However, we observed significantly higher investments, compared to the self-interest Nash prediction, both under symmetric and asymmetric conditions. With asymmetric sharing rules both types of players, even the weak one, invest more than predicted by Nash equilibrium. Nonetheless, overinvestment is higher among strong players. To better understand these results, we examined the players' expectations of their partners' choices. These are surprisingly consistent with the actual investments undertaken.

As game theoretical analysis based on selfish players does not perform too well, we explored the predictions and implications of different behavioural theories, namely: inequity aversion, social welfare and competitive preferences. We showed that players' investment behaviour is consistent with the hypothesis that individuals are concerned with social efficiency. Interestingly, the players' choices cannot be explained by either inequity aversion or competitive preferences. This is an important result, which confirms the main findings of Charness and Rabin (2002) in the context of an incomplete contract situation.

Finally we examined situations where the power structure is flexible. Here we find that players choose symmetric contracts in situations where selfish players would stay with an asymmetric contract. Again these choices are in line with preferences for social efficiency. However, we found 
that this preference must be mainly rooted in the stronger player (a larger $\rho$ and a smaller $\sigma$ in the context of the model by Charness and Rabin).

\section{References}

Adelman, Jeremy (1994), Frontier Development: Land, Labour, and Capital on the Wheatlands of Argentina and Canada, 1890-1914. Oxford University Press.

Andreoni, James and John Miller (2002), "Giving according to garp: An experimental test of the consistency of preferences for altruism." Econometrica, 70, 737-753, URL.

Bolton, Gary E. and Axel Ockenfels (2000), "Erc: A theory of equity, reciprocity, and competition." The American Economic Review, 90, 166-193, URL.

Cabrales, Antonio, Raffaele Miniaci, Marco Piovesan, and Giovanni Ponti (2010), "Social preferences and strategic uncertainty: An experiment on markets and contracts." American Economic Review, 100, 2261-78, URL.

Charness, Gary and Brit Grosskopf (2001), "Relative payoffs and happiness: An experimental study." Journal of Economic Behavior \& Organization, 45, 301-328, URL.

Charness, Gary and Matthew Rabin (2002), "Understanding Social Preferences with Simple Tests." Quarterly Journal of Economics, 117, 817-869, URL,

Corry, Stephen (1993), "The rainforest harvest: Who reaps the benefit?" Ecologist, 23, 148-153.

Cox, James C., Daniel Friedman, and Steven Gjerstad (2007), "A tractable model of reciprocity and fairness." Games and Economic Behavior, 59, 17-45, URL.

Cox, James C. and Vjollca Sadiraj (2011), “Direct tests of individual preferences for efficiency and equity." Economic Inquiry, no-no, URL

Ellingsen, Tore and Magnus Johannesson (2004a), "Is there a hold-up problem?" Scandinavian Journal of Economics, 106, 475-494, URL.

Ellingsen, Tore and Magnus Johannesson (2004b), “Promises, threats and fairness." Economic Journal, 114, 397-420, URL

Engelmann, Dirk and Martin Strobel (2004), "Inequality aversion, efficiency, and maximin preferences in simple distribution experiments." American Economic Review, 94, 857-869, URL.

Faravelli, Marco, Oliver Kirchkamp, and Helmut Rainer (2010), "Social welfare versus inequality aversion in an incomplete contract experiment." CESifo Working Paper Series 2933, CESifo.

Fehr, Ernst, Oliver Hart, and Christian Zehnder (2011), "Contracts as reference pointsExperimental evidence." American Economic Review, 493-525.

Fehr, Ernst, Susanne Kremhelmer, and Klaus M. Schmidt (2008), "Fairness and the Optimal Allocation of Property Rights." The Economic Journal, 118, 1262-1284, URL.

Fehr, Ernst and Klaus M. Schmidt (1999), "A theory of fairness, competition, and cooperation." The Quarterly Journal of Economics, 114, 817-868.

Fischbacher, Urs (2007), “z-Tree: Zurich toolbox for ready-made economic experiments.” Experimental Economics, 10, 171-178, URL. 
Fisman, Raymond, Shachar Kariv, and Daniel Markovits (2007), "Individual preferences for giving." American Economic Review, 97, 1858-1876, URL.

Gächter, Simon, Daniele Nosenzo, Elke Renner, and Martin Sefton (2009), "Sequential versus simultaneous contributions to public goods: Experimental evidence." Technical Report 2602, CESifo Working Paper Series.

Gantner, Anita, Werner Güth, and Manfred Königstein (2001), “Equitable choices in bargaining games with joint production." Journal of Economic Behavior and Organization, 46, 209-225.

Greiner, Ben (2004), "An online recruitment system for economic experiments." In Forschung und wissenschaftliches Rechnen (Kurt Kremer and Volker Macho, eds.), volume 63, of GWDG Bericht, 79-93, Ges. für Wiss. Datenverarbeitung, Göttingen.

Grossman, Sanford J. and Oliver D. Hart (1986), “The Costs and Benefits of Ownership: A Theory of Vertical and Lateral Integration." The Journal of Political Economy, 94, 691-719.

Hacket, Steven C. (1994), "Is relational exchange possible in the absence of reputations and repeated contact." The Journal of Law, Economics and Organization, 10, 360-389, URL.

Hart, Oliver (1995), Firms, contracts, and financial structure. Oxford: Clarendon Press.

Hart, Oliver (2008), "Reference Points and the Theory of the Firm." Economica, 75, 404-411, URL

Hart, Oliver and John Moore (1990), "Property Rights and the Nature of the Firm." Journal of Political Economy, 98, 1119-1158.

Hart, Oliver and John Moore (2008), "Contracts as Reference Points." Quarterly Journal of Economics, 123, 1-48, URL.

Holt, Charles A. and Susan K. Laury (2008), "Voluntray provision of public goods: Experimental results with interior nash equilibria." In The Handbook of Experimental Economics Results (C.R. Plott and V.R. Smith, eds.), Elsevier.

Iriberri, Nagore and Pedro Rey-Biel (2008), "Elicited beliefs and social information in modified dictator games: What do dictators believe other dictators do?" Economics Working Papers 1137, Department of Economics and Business, Universitat Pompeu Fabra, URL.

Klein, Benjamin, Robert G. Crawford, and Armen A. Alchian (1978), "Vertical Integration, Appropriable Rents, and the Competitive Contracting Process." The Journal of Law and Economics, 21, 297-326, URL,

Kritikos, Alexander and Friedel Bolle (2001), "Distributional concerns: Equity- or efficiencyoriented?" Economics Letters, 73, 333-338, URL

Mayers, James and Sonja Vermeulen (2002), “Company-community forestry partnerships: From raw deals to mutual gains? Instruments for sustainable private sector forestry series." Technical report, London: International Institute for Environment and Development (IIED), URL.

Morsello, Carla (2006), "Company-community non-timber forest product deals in the Brazilian Amazon: A review of opportunities and problems." Forest Policy and Economics, 8, 485-494, URL.

Oosterbeek, Hessel, Joep Sonnemans, and Susan van Velzen (2003), “The need for marriage contracts: An experimental study." Journal of Population Economics, 16, 431-453, URL. 
R Development Core Team (2011), R: A Language and Environment for Statistical Computing. R Foundation for Statistical Computing, Vienna, Austria, URL. ISBN 3-900051-07-0.

Tomlinson, B.R. (1996), The Economy of Modern India, 1860-1970. Cambridge University Press, URL

Turner, Terence (1995), “Neoliberal Ecopolitics and Indigenous Peoples: The Kayapó, The "Rainforest Harvest", and The Body Shop." Yale F E ES Bulletin, 98, 113-127, URL

Varian, Hal R. (1994), "Sequential contributions to public goods." Journal of Public Economics, 53, 165-186.

\section{A. List of independent observations}

\begin{tabular}{lrc} 
date & participants & configuration \\
\hline $080612-1643-1$ & 8 & no conflict \\
$080619-1008-1$ & 14 & no conflict \\
$080624-1010-1$ & 8 & conflict \\
$080624-1010-2$ & 10 & conflict \\
$080624-1558-1$ & 8 & conflict \\
$080624-1558-2$ & 10 & conflict \\
$080625-1009-1$ & 8 & conflict \\
$080625-1009-2$ & 8 & conflict \\
$080702-1019-1$ & 8 & conflict \\
$080702-1019-2$ & 10 & conflict \\
$080702-1155-1$ & 8 & no conflict \\
$080702-1155-2$ & 10 & no conflict \\
$080703-1009-1$ & 8 & no conflict \\
$080703-1009-2$ & 10 & no conflict \\
$080703-1207-1$ & 8 & no conflict \\
$080703-1207-2$ & 10 & no conflict
\end{tabular}

\section{B. Conducting the experiment and instructions}

The experiment was run at the Laboratory of the School of Economics at the University of Jena. Participants were recruited by email with Orsee (Greiner. 2004) and could register for the experiment on the internet. At the beginning of the experiment participants drew balls from an urn to determine their allocation to seats. When seated participants then obtained written instructions in German. In the following we give a translation of the instructions.

After answering control questions on the screen subjects entered the treatments described in the instructions. After completing the treatments they answered a short questionnaire on the screen and where then paid in cash. The experiment was done with the help of z-Tree (Fischbacher (2007)).

\section{Instructions to the experiment}

You are participating in a scientific experiment that is sponsored by the University of Jena and the University of St Andrews in Scotland. The instructions are simple. If you read them carefully then you can-depending on your decision-gain a considerable amount of money which is paid to you at the end of the game. 
Your payoff depends on your success in the experiment. During the experiment you gain a certain number of "ECU" (Experimental Currency Units). At the end of the experiment you will be paid in $€$. The conversion rate is $1 €=2000$ ECU.

When you have questions, then please raise your hand. We will come to you and answer your question. All participants of the experiment receive the same instructions. The information on the screen is, however, only for the individual participant. You are not allowed to have a look at the screen of other participants and you are not allowed to talk to other participants. Please concentrate on the experiment, do not read anything you brought with you, do not try to start any other programs on the computer, do not use your mobile phone. If you do not follow these rules you are excluded from the experiment and you will not be paid.

You will play several rounds. In each round you play together with a randomly selected other player. In each round you and the other player choose each one number. Depending on the numbers you choose you receive a payoff in "ECU" which is determined according to a table. The following example shows only a part of a table, in the experiment you see a complete table.

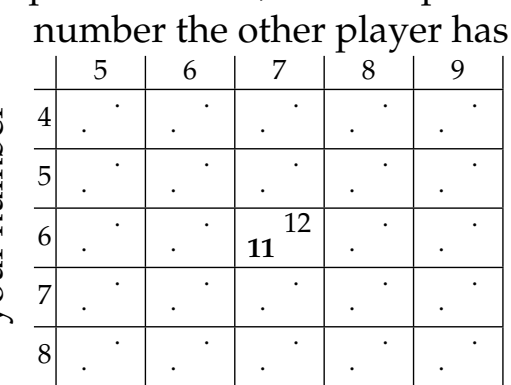

With your number you choose a row in the table. The other player chooses with his number a column in the table. The intersection determines a cell. In the example, when you choose row 6 and the other player column 7, then your payoff is according to the cell 11 . Your payoff is the boldface number at the bottom left (11), the payoff of the other player is the number at the top right (12). With the help of the table you can determine your payoff for any combination of rows and columns. Your payoff is, hence, determined by the number you have chosen and by the number the other player has chosen.

To help you understand the experiment, please do the following:

- Click a number at the beginning of row as well as a number at the top of a column. The row and the column will be shown in red. The cell at the intersection will be circled.

The row you have chosen corresponds to your number. The column you have chosen corresponds to the number you expect the other player will chose.

- Of course, your expectation of what number the other player might choose neither affects your payoff nor the payoff of the other player. To make a good decision, you can nevertheless think about the possible choices of the other player.

- You can repeat this exercise as often as you wish. You can try different combinations of numbers for yourself and for the other player. When you are satisfied with your choice please push the button $\mathrm{OK}$.

As soon as the other player has completed his decision you see on your screen which number he has chosen and which payoff he has received.

Please write these values in each round into the table that you find on the back of this instruction sheet.

Please copy your results from the game into this table (ignore superfluous columns) 


\begin{tabular}{|l|l|l|l|l|l|l|l|}
\hline round & your number & $\begin{array}{l}\text { number of the other } \\
\text { player }\end{array}$ & $\begin{array}{l}\text { your expected } \\
\text { number of the other } \\
\text { player }\end{array}$ & your profit & $\begin{array}{l}\text { profit of the other } \\
\text { player }\end{array}$ & chosen table & used table \\
\hline & & & & & & & \\
\hline & & & & & & & \\
\hline
\end{tabular}

$\vdots$

\section{Statistical software}

The analysis of the data was done with $R$ ( $\mathrm{R}$ Development Core Team, 2011).

- R version 2.15.0 (2012-03-30), x86_64-pc-linux-gnu

- Locale: LC_CTYPE=en_GB . utf 8, LC_NUMERIC=C, LC_TIME=en_GB . utf 8 , LC_COLLATE=en_GB . utf8, LC_MONETARY=en_GB . utf 8, LC_MESSAGES=en_GB . utf8, LC_PAPER=C, LC_NAME=C, LC_ADDRESS=C, LC_TELEPHONE=C, LC_MEASUREMENT=en_GB . utf 8 , LC_IDENTIFICATION $=\mathrm{C}$

- Base packages: base, datasets, graphics, grDevices, methods, splines, stats, utils

- Other packages: alphahull 0.2-1, boot 1.3-4, cacheSweave 0.6-1, corpcor 1.6.2, filehash 2.2-1, geepack 1.1-6, Hmisc 3.9-3, lattice 0.20-6, latticeExtra 0.6-19, lme4 0.999375-42, MASS 7.3-18, Matrix 1.0-6, mitools 2.1, nlme 3.1-104, RColorBrewer 1.0-5, relaimpo 2.2, sgeostat 1.0-24, sp 0.9-98, splancs 2.01-31, stashR 0.3-5, survey 3.28, survival 2.36-14, tikzDevice 0.6.2, tripack 1.3-4, xtable 1.7-0

- Loaded via a namespace (and not attached): cluster 1.14.2, digest 0.5.2, grid 2.15.0, stats4 2.15.0, tools 2.15.0 